Article

\title{
Research on the Hydrophilicity of Non-Coal Kaolinite and Coal Kaolinite from the Viewpoint of Experiments and DFT Simulations
}

\author{
Peng $\mathrm{Xi}^{1, *} \mathbb{0}$, Ruixin $\mathrm{Ma}^{1, *}$ and Wenli Liu ${ }^{2}$ \\ 1 Department of Environmental Engineering, North China Institute of Science and Technology, \\ Beijing 101601, China \\ 2 School of Chemical and Environmental engineering, China University of Mining and Technology (Beijing), \\ Beijing 100083, China; lwl@cumtb.edu.cn \\ * Correspondence: pengxi@ncist.edu.cn (P.X.); maruixin@ncist.edu.cn (R.M.)
}

Received: 18 June 2020; Accepted: 19 July 2020; Published: 21 July 2020

\begin{abstract}
Coal is often coated by coal kaolinite in flotation, resulting in an increase in concentrate ash. The natural hydrophilicity of minerals is the key factor to determining its flotation behavior. The results of studies on the contact angle of non-coal kaolinite and coal kaolinite samples found that the contact angle of coal kaolinite was bigger than that of non-coal kaolinite and the hydrophilicity of the latter was stronger. To investigate the mechanism of the hydrophilic difference between non-coal kaolinite and coal kaolinite, the adsorption of a single water molecule on non-coal kaolinite and coal kaolinite (100) and $(00 \overline{1})$ surfaces was calculated with the first principle method of the density functional theory (DFT). The calculation results showed that hydrogen bonds were formed between the hydrogen atom and the oxygen atom of the surface and the hydrogen atom and the oxygen atom of the water molecule after the water molecule was adsorbed on the kaolinite (100) and (001) surface. The adsorption process of water molecules on the kaolinite surface was physical adsorption with Van der Waals force existing between them. Regardless of whether the kaolinite (001) surface or the kaolinite $(00 \overline{1})$ surface was doped with a carbon atom, the adsorption of a single water molecule was weakened, with a weaker hydrogen bond formed. The calculated results explained the difference of hydrophilicity between non-coal kaolinite and coal kaolinite samples from the molecular and atomic viewpoint.
\end{abstract}

Keywords: hydrophilicity; kaolinite; DFT; floatability; symmetry structure

\section{Introduction}

Flotation is a separation method to separate one mineral from another based on the differences in their hydrophilicity within an ore [1]. With the depth of coal and mechanized mining, the increase of high-ash slime resulted in the increase of concentrate ash in the flotation process. The high-ash coal slime was mainly composed of clay minerals, which were mostly composed of coal kaolinite [2]. The coal kaolinites are easily argillized to form fine particles when they interact with water molecules in water. They easily agglomerate with the target minerals (coal) in the flotation process and cover the latter. They also easily enter into the concentrate with the mechanical entrainment of the foam water and the entrainment of the concentrate so that the selectivity of the separation process is affected and the quality of the flotation concentrate is reduced. The mechanism of argillization should be explored and can be studied by simulating the adsorption process of one water molecule on the different surfaces of kaolinite. The gangue minerals mainly entered the froth layer through entrainment, and the dissociated fine particles were recovered in the concentrate tank with a thin water layer between the 
bubbles, which had nothing to do with the surface hydrophilicity of the particles [3,4]. The entrainment rate of fine slime was directly related to the recovery of water and increased with the increase of fine particle size $[5,6]$. It was found that the coal was coated by clay slime, which led to the increase of the microflotation concentrate's ash content with the existence of clay minerals, and the effects were more distinct in the presence of $\mathrm{Ca}^{2+}$ [7]. In addition, the natural hydrophilicity of minerals is the key factor to determining their flotation behavior. The same is true for coal kaolinite. The properties (hydrophilicity) of minerals were usually determined by their own structure, closely related to their lattice defects. The previous study [8] found that the carbon defects existed in the lattice of coal kaolinites. Then, the surface hydrophilicity and other properties changed, which affected their flotation behavior finally. To remove the coal kaolinite during the flotation process efficiently and explore efficient dispersants and inhibitors, it was very important for the subsequent deashing and improved selectivity of mineral flotation to study the hydrophilicity of the coal kaolinite surface and its forming mechanism. However, there are fewer research studies about the effect of crystal structure on the coal kaolinite's intrinsic hydrophilicity from the molecular and atomic viewpoints.

The density functional theory (DFT) was widely used to study the mechanism of intrinsic hydrophilicity by calculating the adsorption of one water molecule on different mineral surfaces. It was found that the hydrophilicity of coal pyrite was weakened gradually following surface oxidation based on the DFT in the previous study [9]. The farther the adsorption position of the water molecule is from the defect, the greater the adsorption energy is. The hydrophilicity at the doping-position, ortho-position, and meta-position of the coal pyrite (100) surface was weakened due to the existence of carbon defects $[10,11]$. When the coal pyrite was covered by coal, the coal pyrite became hydrophobic instead of hydrophilic, and the mechanism was revealed by calculating the adsorption process of one single water molecule on a different piece of coal pyrite [12,13]. The adsorption energy of a single water molecule on a kaolinite surface doped with $\mathrm{Mg}$, $\mathrm{Ca}$, and Fe was smaller than that of the undoped kaolinite. The water molecule preferentially adsorbed on the Mg-doped surface [14]. It showed that the hydrogen bond was mainly formed after the single water molecule was adsorbed on the kaolinite (001) and $(00 \overline{1})$ surfaces, and it was easier for the water molecule to adsorb on the kaolinite (001) surface [15].

The hydrophilicity of kaolinites from different mining areas are compared through contact angle experiments. Based on the previously built models of non-coal kaolinite and coal kaolinite [8], the adsorption of a single water molecule on an undoped kaolinite surface and a kaolinite surface doped by carbon atoms is compared by analysis of the adsorption energy, bond, charge transfer, and DOS with the first principle method of DFT. The mechanism of the hydrophilicity difference between non-coal and coal kaolinite is revealed at the molecular and atomic levels.

\section{Samples and Methods}

\subsection{Samples}

The kaolinite samples, typically from different mining areas of China, were taken as the research object [8]. XRD of all samples was conducted using the Bruker D8 ADVANCE X-ray diffractometer and the samples needed to be ground under 200 mesh before testing. The results are shown in Figure 1. There were kaolinite minerals in all of the kaolinite samples. X-ray fluorescence spectrometry (XRF) was performed with the ARL ADVANT'X IntelliPower ${ }^{\mathrm{TM}} 3600$ of Thermo Fisher Scientific. The results are shown in Table 1 . The contents of $\mathrm{SiO}_{2}$ and $\mathrm{Al}_{2} \mathrm{O}_{3}$ were about $98 \%$ in the powder non-coal kaolinite from Zhangjiakou and the lump and powder coal kaolinites from the other three areas. The kaolinite samples were all very pure, and were taken as the minerals for the follow-up contact angle test. 


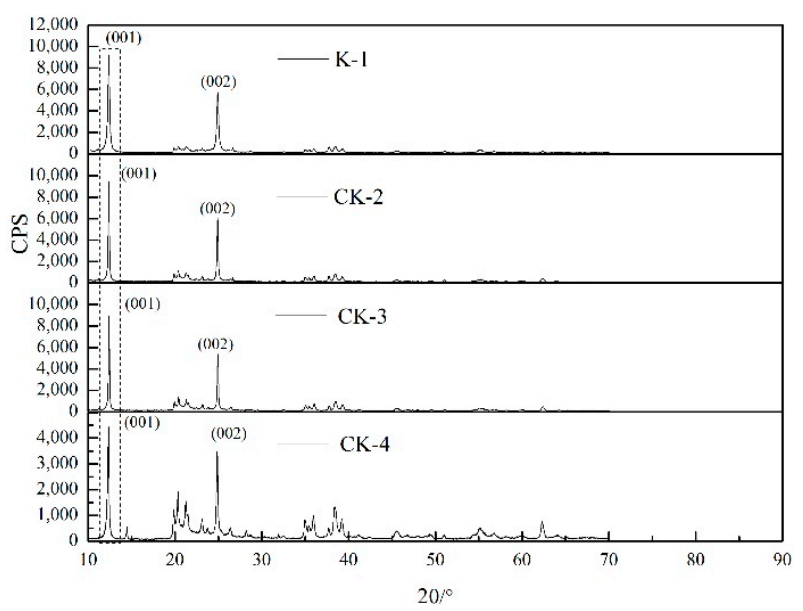

Figure 1. XRD of all kaolinite samples.

Table 1. Experimental samples and their composition.

\begin{tabular}{cccccccccc}
\hline $\begin{array}{c}\text { Sample } \\
\text { Number }\end{array}$ & $\mathrm{SiO}_{2} / \%$ & $\mathrm{Al}_{2} \mathrm{O}_{3} / \%$ & $\mathrm{TiO}_{2} / \%$ & $\mathrm{Fe}_{2} \mathrm{O}_{3} / \%$ & $\mathbf{P}_{2} \mathrm{O}_{5} / \%$ & $\mathrm{CaO} / \%$ & $\mathbf{N a}_{2} \mathrm{O} / \%$ & $\mathbf{M g O} / \%$ & Remarks \\
\hline $\mathrm{K}-1$ & 54.76 & 43.16 & 0.69 & 0.56 & 0.01 & 0.03 & 0.09 & 0.16 & Powder, Zhangjiakou \\
$\mathrm{CK}-2$ & 54.10 & 44.60 & 0.43 & 0.18 & 0.01 & 0.09 & 0.02 & 0.04 & Lump, Datong \\
$\mathrm{CK}-3$ & 54.05 & 44.41 & 0.46 & 0.21 & 0.02 & 0.37 & 0.06 & 0.09 & Lump, Huairen \\
$\mathrm{CK}-4$ & 52.17 & 45.32 & 0.68 & 0.58 & 0.40 & 0.26 & 0.19 & 0.13 & Powder, Huaibei \\
\hline
\end{tabular}

\subsection{Experimental Equipment and Methods}

The wettability of a mineral's surface refers to its wettability degree when the water contacts with it. Usually the contact angle is used to indicate the wettability. The larger the contact angle is, the worse the wettability is [16].

The contact angle test was carried out using the SL150 Optical contact angle meter made by America Kono Group, under the conditions of $101.3 \mathrm{kPa}$ and $20^{\circ} \mathrm{C}$. To ensure the accuracy of the experiment, all samples were pressed into four $\mathrm{H}_{3} \mathrm{BO}_{3}$ pellets (with $20 \mathrm{wt} \%$ per sample) with a tableting machine, and a distilled water droplet was dropped on the surface of each pellet with a microinjector. The whole process of the water drops falling and adhering to the pellet surface was captured by a high-definition camera. Four different areas of each pellet were measured using the sessile drop method [17]. All kaolinite samples needed to be dried at $105^{\circ} \mathrm{C}$ for $4 \mathrm{~h}$ before they were measured. Due to the high hydrophilicity of the kaolinite tablets, the water drops were absorbed particularly fast after they were dropped on the surface. Therefore, the selected image used to analyze the contact angle was the one taken at the uniform time just after the water drop fell on the tablet surface.

\subsection{Computational Methods and Models}

\subsubsection{Computational Methods}

All of the calculations were performed with the Cambridge Sequential Total Energy Package (CASTEP) module in the Materials Studio software [18]. The interactions between valence electrons and the ionic core were represented with the method of ultrasoft pseudopotentials [19]. The exchangecorrelation function taken was the generalized gradient approximation-Perdew-Burke-Ernzerhof (GGA-PBE) functional. The value of the cutoff energy was $400 \mathrm{eV}$. The density functional theory dispersion (DFT-D) correction was also used to characterize the adsorption of a molecule on a slab model $[20,21]$. The other specific parameters and computational methods that needed to be set and adopted were identified by reference to the just-published paper [8]. The parameters and computational methods adopted in the process of optimizing one single water molecule were set according to the method for optimizing a single atom [8]. 


\subsubsection{Surface Model}

The optimized single-layer model of the kaolinite $(001)$ and $(00 \overline{1})$ surfaces was directly obtained from Han [22], as shown in Figure 2a. The vacuum thickness of the periodic supercell $(2 \times 1 \times 1)$ we used in the calculation process was $20 \AA$. Stable models of the coal kaolinite (001) and $(00 \overline{1})$ surfaces containing carbon defects were obtained from the previous study [8] and are shown in Figure $2 b, c$, respectively.

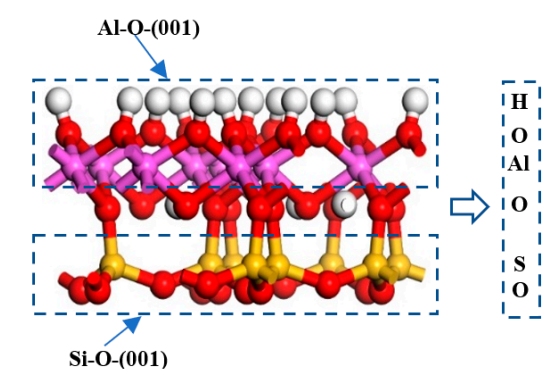

(a)

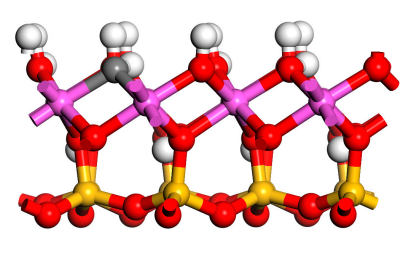

(b)

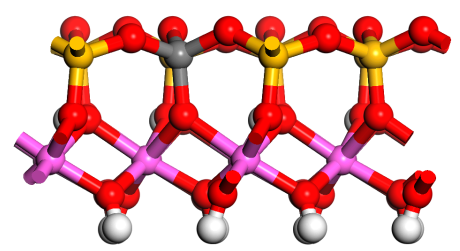

(c)

Figure 2. Model of the single-layer kaolinite surface. (a) (001) surface; (b) (001) surface containing carbon defects; (c) (001) surface containing carbon defects.

\subsubsection{The Adsorption Energy}

The interaction between the water molecule and the kaolinite surface was evaluated by the adsorption energy $\left(E_{a d s}\right)$, which was calculated as:

$$
E_{\text {ads }}=E_{\text {Total }}-\left(E_{\mathrm{H}_{2} \mathrm{O}}+E_{\text {Surface }}\right)
$$

where $E_{a d s}$ is the adsorption energy in $\mathrm{kJ} / \mathrm{mol}, E_{\text {Total }}$ is the energy of the kaolinite (001) or (001) surface with a single water molecule adsorbed in $\mathrm{kJ} / \mathrm{mol}$, and $E_{\text {Surface }}$ is the energy of the undoped and C-doped kaolinite (001) or (00) $\overline{1})$ surface in $\mathrm{kJ} / \mathrm{mol}$.

$E_{\mathrm{H}_{2} \mathrm{O}}$ is the energy of one single water molecule in a $20 \times 20 \times 20$ cubic box in $\mathrm{kJ} / \mathrm{mol}$.

\section{Results and Discussion}

\subsection{Contact Angle}

The natural floatability is characterized by the wettability of the mineral surface and measured by the contact angle. The contact angles of non-coal kaolinite and coal kaolinite were measured, with the results shown in Table 2.

The measured contact angles between a liquid and the solid surface of all kaolinite surfaces were between 17 and $25^{\circ}$, which is much less than $90^{\circ}$ and suggests that all kaolinite surfaces were superhydrophilic. Compared with the non-coal kaolinite, the contact angles of the coal kaolinites were a little bigger, by about $1.5-3.5^{\circ}$, which suggested that the natural hydrophilicity of the coal kaolinites was a little weaker. It demonstrated that the hydrophilicity of some of the coal kaolinite surface's parts weakened, probably due to their structural changes (such as carbon defects [8]), resulting in the overall reduction of hydrophilicity. It was more difficult for the water molecules to adsorb on the surface of the coal kaolinites.

To investigate the mechanism of the hydrophilic differences between the above two kinds of kaolinite, the adsorption of a single water molecule on different kaolinite surfaces was simulated with the method of DFT calculation. 
Table 2. Contact angle results of kaolinites.

\begin{tabular}{|c|c|c|c|c|c|c|c|}
\hline \multirow{2}{*}{ Sample } & \multirow{2}{*}{$\begin{array}{l}\text { Sample } \\
\text { Number }\end{array}$} & \multirow{2}{*}{$\begin{array}{l}\text { Sample } \\
\text { Number }\end{array}$} & \multicolumn{4}{|c|}{ Location and Results $/^{\circ}$} & \multirow{2}{*}{$\begin{array}{l}\text { Mean } \\
\text { Value } /{ }^{\circ}\end{array}$} \\
\hline & & & 1 & 2 & 3 & 4 & \\
\hline \multirow{5}{*}{ Kaolinite } & \multirow{5}{*}{ K-1 } & $\mathrm{A}$ & 18.90 & 19.80 & 18.10 & 18.50 & 18.83 \\
\hline & & B & 20.00 & 20.60 & 22.60 & 18.40 & 20.40 \\
\hline & & C & 20.10 & 20.50 & 18.90 & 21.30 & 20.20 \\
\hline & & $\mathrm{D}$ & 17.00 & 19.60 & 19.40 & 19.30 & 18.83 \\
\hline & & Mean value & \multicolumn{4}{|c|}{19.56} & \\
\hline \multirow{15}{*}{ Coal kaolinite } & \multirow{5}{*}{ CK-2 } & $\mathrm{A}$ & 22.00 & 20.40 & 22.20 & 20.70 & 21.33 \\
\hline & & $\mathrm{B}$ & 21.80 & 21.20 & 21.20 & 18.30 & 20.63 \\
\hline & & $\mathrm{C}$ & 20.00 & 19.30 & 19.80 & 19.10 & 19.55 \\
\hline & & $\mathrm{D}$ & 21.20 & 23.80 & 23.50 & 23.40 & 22.98 \\
\hline & & Mean value & \multicolumn{4}{|c|}{21.12} & \\
\hline & \multirow{5}{*}{ CK-3 } & A & 24.10 & 24.20 & 23.40 & 23.70 & 23.85 \\
\hline & & B & 23.00 & 21.50 & 23.90 & 22.20 & 22.65 \\
\hline & & C & 22.80 & 23.10 & 23.50 & 23.00 & 23.10 \\
\hline & & $\mathrm{D}$ & 22.40 & 22.10 & 23.10 & 22.60 & 22.55 \\
\hline & & Mean value & \multicolumn{4}{|c|}{23.04} & \\
\hline & \multirow{5}{*}{ CK-4 } & $\mathrm{A}$ & 24.00 & 25.00 & 25.00 & 25.00 & 23.13 \\
\hline & & B & 24.00 & 23.50 & 23.00 & 22.00 & 24.75 \\
\hline & & $\mathrm{C}$ & 20.00 & 20.50 & 20.00 & 20.00 & 20.13 \\
\hline & & D & 20.50 & 21.50 & 23.00 & 20.80 & 21.20 \\
\hline & & Mean value & \multicolumn{4}{|c|}{22.30} & \\
\hline
\end{tabular}

\subsection{Adsorption Configuration and Adsorption Energy}

It was found that the adsorption model of a single water molecule $\left(\mathrm{H}_{2} \mathrm{O}\right)$ on the kaolinite $(001)$ and $(00 \overline{1})$ surfaces, provided by Han, in Figure $3 a, c$ was the most stable [22]. The models were used as the basic configuration to investigate the influence of a C-defect on the adsorption of a single water molecule on the kaolinite surface. The adsorption configuration and adsorption energy of $\mathrm{H}_{2} \mathrm{O}$ on different kaolinite surfaces are shown in Figure 3 and Table 3. The number in the graph represents the distance between bonding atoms, whose unit is $\AA$.

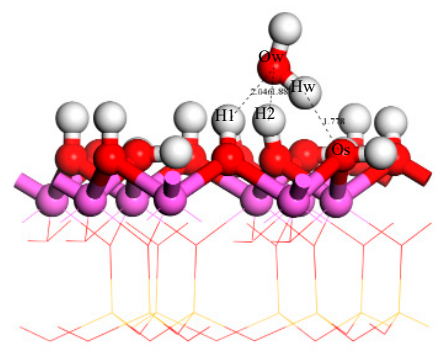

(a)

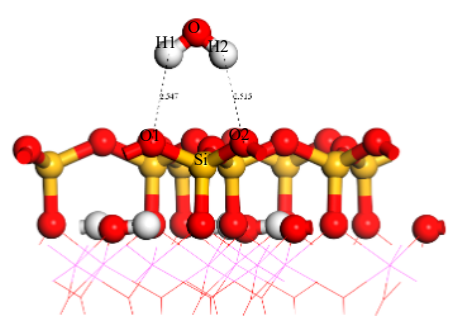

(c)

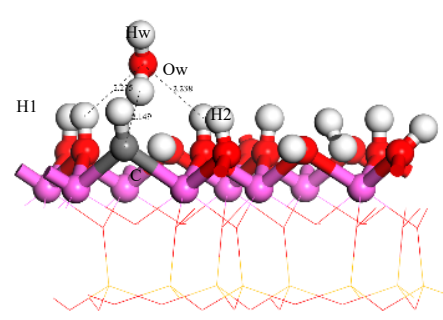

(b)

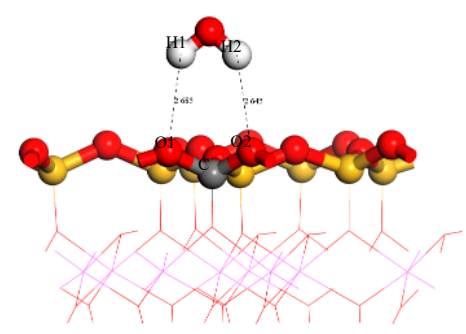

(d)

Figure 3. Adsorption Configurations of $\mathrm{H}_{2} \mathrm{O}$ on the kaolinite surface: (a) $\mathrm{H}_{2} \mathrm{O} /(001)$ surface; (b) $\mathrm{H}_{2} \mathrm{O} /(001)$ surface (C-defect); (c) $\mathrm{H}_{2} \mathrm{O} /(00 \overline{1})$ surface; (d) $\mathrm{H}_{2} \mathrm{O} /(00 \overline{1})$ surface (C-defect). 
Table 3. Adsorption energy of $\mathrm{H} 2 \mathrm{O}$ on the different kaolinite surfaces.

\begin{tabular}{cc}
\hline Adsorption Model & $\mathbf{E}_{\mathbf{a d s}} / \mathbf{k J} / \mathbf{m o l}$ \\
\hline $\mathrm{H}_{2} \mathrm{O} /(001)$ surface & -65.73 \\
$\mathrm{H}_{2} \mathrm{O} /(001)$ surface $(\mathrm{C}$ defect $)$ & -13.90 \\
\hline $\mathrm{H}_{2} \mathrm{O} /(00 \overline{1})$ surface & -19.38 \\
$\mathrm{H}_{2} \mathrm{O} /(00 \overline{1})$ surface $(\mathrm{C}$ defect $)$ & -17.22 \\
\hline
\end{tabular}

The $E_{\text {ads }}$ of a single water molecule on the undoped kaolinite (001) and (001) surfaces was $-65.73 \mathrm{~kJ} / \mathrm{mol}$ and $-19.38 \mathrm{~kJ} / \mathrm{mol}$, respectively, which was very close to the results of many scholars [20,23]. It demonstrated that the model was accurate. The water molecule could spontaneously adsorb on the undoped kaolinite (001) and (001) surfaces and the entire adsorption process of the water molecule was exothermic. The former was more stable. From the macroscopic viewpoint, the kaolinite surface was hydrophobic and had difficultly floating during the slime flotation.

After $\mathrm{H}_{2} \mathrm{O}$ adsorbed on the C-defect kaolinite surface, whether the (001) surface or the $(00 \overline{1})$ surface, the adsorption energy of both became small, from -65.73 to $-13.90 \mathrm{~kJ} / \mathrm{mol}$ and from -19.38 to $-17.22 \mathrm{~kJ} / \mathrm{mol}$, respectively, in Table 3. The physical adsorption strength of the single water molecule at the carbon-atom-doped position of the kaolinite surface decreased in the presence of carbon atom defects so that the overall hydrophilicity of the doped kaolinite weakened, which explained the difference in hydrophilicity of the above two kinds of kaolinites.

\subsection{Analysis of Bonding}

Furthermore, we calculated the bond Mulliken population [24] and length between the water molecule and different kaolinite surfaces, as shown in Table 4.

Table 4. Bond Mulliken population and length after water adsorption.

\begin{tabular}{cccc}
\hline Adsorption Model & Bond & Bond Population & Bond Length/̊ \\
\hline \multirow{2}{*}{$\mathrm{H}_{2} \mathrm{O} /(001)$ surface } & $\mathrm{H}_{1}-\mathrm{O}_{\mathrm{w}}$ & 0.04 & 2.046 \\
& $\mathrm{H}_{2}-\mathrm{O}_{\mathrm{w}}$ & 0.05 & 1.880 \\
& $\mathrm{H}_{\mathrm{w}}-\mathrm{O}_{\mathrm{s}}$ & 0.10 & 1.776 \\
\hline \multirow{2}{*}{$\mathrm{H}_{2} \mathrm{O} /(001)$ surface $(\mathrm{C}$ defect $)$} & $\mathrm{H}_{1}-\mathrm{O}_{\mathrm{w}}$ & 0.01 & 2.275 \\
& $\mathrm{H}_{2}-\mathrm{O}_{\mathrm{w}}$ & 0.01 & 2.238 \\
& $\mathrm{H}_{\mathrm{w}}-\mathrm{C}$ & 0.00 & 2.149 \\
\hline \multirow{2}{*}{$\mathrm{H}_{2} \mathrm{O} /(00 \overline{1})$ surface } & $\mathrm{H}_{1}-\mathrm{O}_{1}$ & 0.00 & 2.547 \\
& $\mathrm{H}_{2}-\mathrm{O}_{2}$ & 0.00 & 2.515 \\
\hline \multirow{2}{*}{$\mathrm{H}_{2} \mathrm{O} /(00 \overline{1})$ surface $(\mathrm{C}$ defect $)$} & $\mathrm{H}_{1}-\mathrm{O}_{1}$ & 0.00 & 2.685 \\
& $\mathrm{H}_{2}-\mathrm{O}_{2}$ & 0.00 & 2.645 \\
\hline
\end{tabular}

For the kaolinite (001) surface, the $\mathrm{O}$ of the surface hydroxyl was bonded with the $\mathrm{H}$ of the water molecule and a strong $\mathrm{H}-\mathrm{O}$ bond was formed, whose bond population was 0.10 . There were also other $\mathrm{H}-\mathrm{O}$ bonds formed between the $\mathrm{H}$ of the hydroxyl and the $\mathrm{O}$ of the water molecule. Compared with the (001) surface, the Mulliken populations of both of the $\mathrm{H}-\mathrm{O}$ bonds formed between the $\mathrm{H}$ of the water molecule and the $\mathrm{O}$ of the kaolinite $(00 \overline{1})$ surface were 0.00 and the bond lengths were longer, which illustrated that there was almost no interaction between the single water molecule and the kaolinite $(00 \overline{1})$ surface. The adsorption process of the water molecules on the kaolinite surface was physical adsorption with a Van der Waals force existing between the adsorbate and the adsorbent.

Regardless of whether or not the water molecule adsorbed on the doped kaolinite (001) or (001) surface by a carbon defect, the $\mathrm{H}-\mathrm{O}$ bond Mulliken population became small and the $\mathrm{H}-\mathrm{O}$ bond length became long. It demonstrated that it was more difficult for the water molecule to adsorb on the C-defect kaolinite surface, consistent with the results of the adsorption energy analysis. 


\subsection{Charge Transfer}

The Mulliken charge population (MCP) [25] refers to the loss and transfer of electrons between the bonding atoms. The MCP results before adsorption (B) and after adsorption (A) of the single water molecule on different kaolinite surfaces are shown in Tables 5 and 6.

Table 5. The Mulliken charge population (MCP) of the bonding atoms between $\mathrm{H}_{2} \mathrm{O}$ and kaolinite surfaces.

\begin{tabular}{|c|c|c|c|c|c|c|c|}
\hline Adsorption Model & Atomic Label & Adsorption Status & $\mathrm{s}$ & $\mathrm{p}$ & d & Total & Charge/e \\
\hline \multirow{10}{*}{$\mathrm{H}_{2} \mathrm{O} /(001)$ surface } & \multirow{2}{*}{$\mathrm{H}_{1}$} & $\mathrm{~B}$ & 0.54 & 0.00 & 0.00 & 0.54 & 0.46 \\
\hline & & $\mathrm{A}$ & 0.55 & 0.00 & 0.00 & 0.55 & 0.45 \\
\hline & \multirow{2}{*}{$\mathrm{H}_{2}$} & B & 0.54 & 0.00 & 0.00 & 0.54 & 0.46 \\
\hline & & $\mathrm{A}$ & 0.55 & 0.00 & 0.00 & 0.55 & 0.45 \\
\hline & \multirow{2}{*}{$\mathrm{O}_{\mathrm{s}}$} & B & 1.85 & 5.19 & 0.00 & 7.04 & -1.04 \\
\hline & & $\mathrm{A}$ & 1.85 & 5.16 & 0.00 & 7.01 & -1.01 \\
\hline & \multirow{2}{*}{$\mathrm{H}_{\mathrm{w}}$} & B & 0.48 & 0.00 & 0.00 & 0.48 & 0.52 \\
\hline & & A & 0.55 & 0.00 & 0.00 & 0.55 & 0.45 \\
\hline & \multirow{2}{*}{$\mathrm{O}_{\mathrm{w}}$} & B & 1.89 & 5.16 & 0.00 & 7.05 & -1.05 \\
\hline & & $\mathrm{A}$ & 1.86 & 5.13 & 0.00 & 7.00 & -1.00 \\
\hline \multirow{8}{*}{$\mathrm{H}_{2} \mathrm{O} /(00 \overline{1})$ surface } & \multirow{2}{*}{$\mathrm{H}_{1}$} & B & 0.48 & 0.00 & 0.00 & 0.48 & 0.52 \\
\hline & & $\mathrm{A}$ & 0.49 & 0.00 & 0.00 & 0.49 & 0.51 \\
\hline & \multirow{2}{*}{$\mathrm{H}_{2}$} & B & 0.48 & 0.00 & 0.00 & 0.48 & 0.52 \\
\hline & & $\mathrm{A}$ & 0.49 & 0.00 & 0.00 & 0.49 & 0.51 \\
\hline & \multirow{2}{*}{$\mathrm{O}_{1}$} & B & 1.84 & 5.32 & 0.00 & 7.16 & -1.16 \\
\hline & & A & 1.84 & 5.33 & 0.00 & 7.17 & -1.17 \\
\hline & \multirow{2}{*}{$\mathrm{O}_{2}$} & B & 1.84 & 5.32 & 0.00 & 7.16 & -1.16 \\
\hline & & A & 1.84 & 5.33 & 0.00 & 7.17 & -1.17 \\
\hline
\end{tabular}

Table 6. $\mathrm{MCP}$ of the bonding atoms between $\mathrm{H}_{2} \mathrm{O}$ and coal kaolinite surfaces.

\begin{tabular}{|c|c|c|c|c|c|c|c|}
\hline Surface & Atomic Label & Adsorption Status & $\mathbf{s}$ & $\mathbf{p}$ & d & Total & Charge/e \\
\hline \multirow{10}{*}{$\begin{array}{c}\mathrm{H}_{2} \mathrm{O} /(001) \text { surface } \\
\text { (C- defect) }\end{array}$} & \multirow{2}{*}{$\mathrm{H}_{1}$} & $\mathrm{~B}$ & 0.54 & 0.00 & 0.00 & 0.54 & 0.46 \\
\hline & & A & 0.55 & 0.00 & 0.00 & 0.55 & 0.45 \\
\hline & \multirow{2}{*}{$\mathrm{H}_{2}$} & $\mathrm{~B}$ & 0.54 & 0.00 & 0.00 & 0.54 & 0.46 \\
\hline & & $\mathrm{A}$ & 0.55 & 0.00 & 0.00 & 0.55 & 0.45 \\
\hline & \multirow{2}{*}{ C } & B & 1.68 & 3.14 & 0.00 & 4.83 & -0.83 \\
\hline & & $\mathrm{A}$ & 1.67 & 3.15 & 0.00 & 4.82 & -0.82 \\
\hline & \multirow{2}{*}{$\mathrm{H}_{\mathrm{w}}$} & $\mathrm{B}$ & 0.54 & 0.00 & 0.00 & 0.54 & 0.46 \\
\hline & & A & 0.54 & 0.00 & 0.00 & 0.54 & 0.46 \\
\hline & \multirow{2}{*}{$\mathrm{O}_{\mathrm{w}}$} & B & 1.89 & 5.16 & 0.00 & 7.05 & -1.05 \\
\hline & & A & 1.87 & 5.10 & 0.00 & 6.97 & -0.97 \\
\hline \multirow{8}{*}{$\begin{array}{l}\mathrm{H}_{2} \mathrm{O} /(00 \overline{1}) \text { surface } \\
\quad(\mathrm{C} \text { - defect) }\end{array}$} & \multirow{2}{*}{$\mathrm{H}_{1}$} & B & 0.48 & 0.00 & 0.00 & 0.48 & 0.52 \\
\hline & & $\mathrm{A}$ & 0.48 & 0.00 & 0.00 & 0.48 & 0.52 \\
\hline & \multirow{2}{*}{$\mathrm{H}_{2}$} & $\mathrm{~B}$ & 0.48 & 0.00 & 0.00 & 0.48 & 0.52 \\
\hline & & $\mathrm{A}$ & 0.48 & 0.00 & 0.00 & 0.48 & 0.52 \\
\hline & \multirow{2}{*}{$\mathrm{O}_{1}$} & B & 1.77 & 5.02 & 0.00 & 6.79 & -0.79 \\
\hline & & $\mathrm{A}$ & 1.77 & 5.03 & 0.00 & 6.80 & -0.80 \\
\hline & \multirow{2}{*}{$\mathrm{O}_{2}$} & B & 1.77 & 5.02 & 0.00 & 6.79 & -0.79 \\
\hline & & A & 1.77 & 5.03 & 0.00 & 6.80 & -0.80 \\
\hline
\end{tabular}


After the undoped kaolinite (001) surface was adsorbed by $\mathrm{H}_{2} \mathrm{O}$, the $\mathrm{O}_{\mathrm{s}} 2 \mathrm{p}$ orbit of the surface hydroxyl lost $0.03 \mathrm{e}$ and the $\mathrm{H}_{\mathrm{w}} 1 \mathrm{~s}$ of the water molecule got $0.07 \mathrm{e}$. The $\mathrm{O}_{\mathrm{w}} 2 \mathrm{p}$ orbit of the water molecule lost $0.05 \mathrm{e}$, and the bonded $\mathrm{H}_{1}$ and $\mathrm{H}_{2}$ 1s orbit of the surface hydroxyl got $0.01 \mathrm{e}$, with the hydrogen bonds $\mathrm{H}_{1}-\mathrm{O}_{\mathrm{w}}$ and $\mathrm{H}_{2}-\mathrm{O}_{\mathrm{w}}$ formed. However, when $\mathrm{H}_{2} \mathrm{O}$ adsorbed on the C-defect kaolinite (001) surface, the $\mathrm{C}$ atom lost only $0.01 \mathrm{e}$ and there was no change in the $\mathrm{H}_{\mathrm{w}} 1 \mathrm{~s}$ of the water molecule. The charge transfer between the $\mathrm{H}_{2} \mathrm{O}$ and the kaolinite surface decreased. It demonstrated that the hydrogen bond formed between the $\mathrm{H}$ of the water molecule and the $\mathrm{O}$ of the kaolinite surface almost disappeared and the interaction between them weakened after the kaolinite (001) surface was doped by the carbon atoms.

After $\mathrm{H}_{2} \mathrm{O}$ was adsorbed on the kaolinite (001) surface, the $\mathrm{H}_{1}$ and $\mathrm{H}_{2}$ 1s orbit of the water molecule and the $\mathrm{O}_{1}$ and $\mathrm{O}_{2} 2 \mathrm{p}$ orbit of the surface got $0.01 \mathrm{e}$, with a very weak hydrogen bond formed. However, when $\mathrm{H}_{2} \mathrm{O}$ adsorbed on the C-defect kaolinite (001) surface, the two $\mathrm{H}$ 1s orbits of the water molecule did not change and the two $\mathrm{O}_{\mathrm{s}} 2 \mathrm{p}$ orbit still got $0.02 \mathrm{e}$ in total. Whether the former or the latter, there was almost no charge transfer between the $\mathrm{H}_{2} \mathrm{O}$ and the kaolinite surface, which explained the formed hydrogen bond population $(0.00)$ and the very small adsorption energy.

According to the charge density and charge density difference map of the single water molecule adsorbed on the kaolinite (001) surface and (001) surface in Figure $4 a, c$, the electrons were mainly gathered around the $\mathrm{O}$ atoms of the water molecule and the kaolinite surface, respectively. After the single water molecule was adsorbed on the kaolinite surface doped by carbon atoms, the electron aggregation around the $\mathrm{O}$ atoms of the water molecule and the doped kaolinite surface reduced, as shown in Figure $4 \mathrm{~b}$,d. It was indicated that the occurrence of the electron accumulation made it possible for the water molecule to adsorb on the kaolinite (001) surface and $(00 \overline{1})$ surface. On the whole, whether it was the kaolinite (001) surface or the kaolinite (001) surface, the charge transferred from the kaolinite to the water molecule. However, after the kaolinite surfaces were doped with carbon atoms, it was more difficult for the water molecule to adsorb on the C-defect kaolinite surface and the interaction between them was weakened, consistent with the results of the bond Mulliken population analysis.

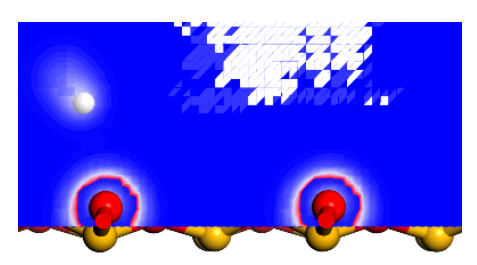

(a)

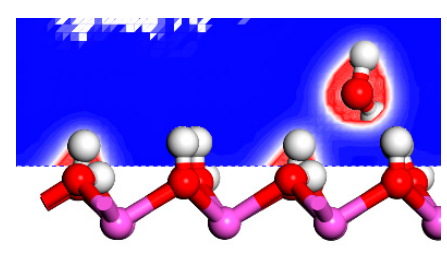

(c)

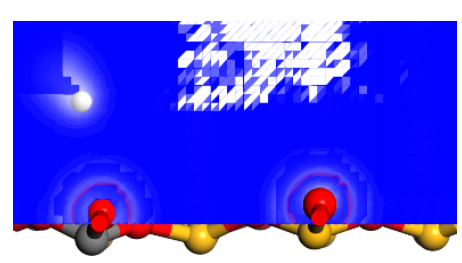

(b)

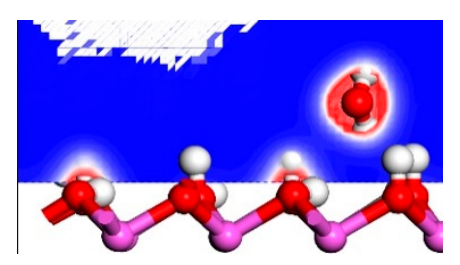

(d)

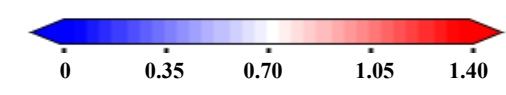

(1) Electron density

Figure 4. Cont. 


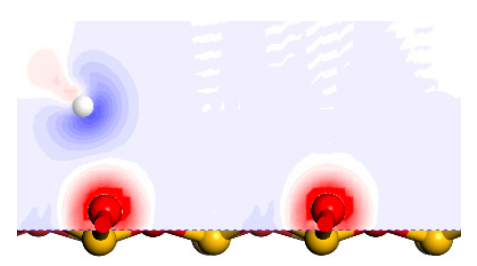

(a)

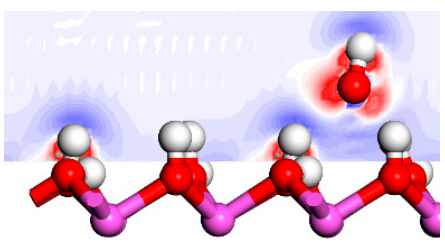

(c)

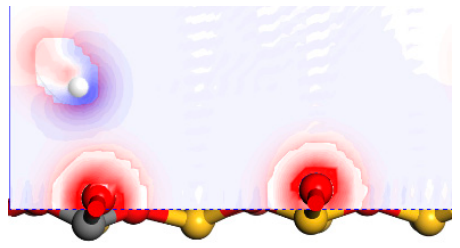

(b)

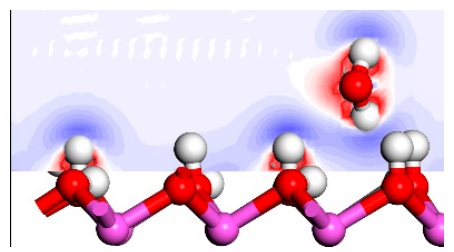

(d)

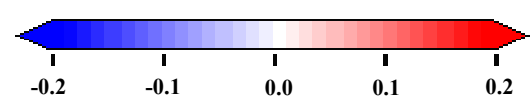

(2) Charge density difference

Figure 4. Electron density and charge density difference map after water molecule adsorption on different kaolinite surfaces: (a) Si-O surface; (b) Si-O surface (C-defect); (c) Al-O surface; (d) Al-O surface (C-defect).

\section{Conclusions}

The mechanism of the hydrophilicity difference between non-coal kaolinite and coal kaolinite was revealed, and the mechanism of argillization was studied from the viewpoint of quantum chemistry by simulating the adsorption process of the water molecules on kaolinite (100) and (001) surfaces.

(1) After the single water molecule was adsorbed on the kaolinite surface doped by a carbon atom, regardless of whether it was the kaolinite (001) surface or the $(00 \overline{1})$ surface, the adsorption energy became small. The presence of carbon atom defects decreased the physical adsorption strength of water molecules at the carbon-atom-doped position of the kaolinite surface.

(2) For the kaolinite (100) and $(00 \overline{1})$ surfaces, hydrogen bonds were formed between the kaolinite surface and the water molecule and the strength of the former was stronger. The adsorption process was physical adsorption with a Van der Waals force existing between them. For the kaolinite (001) surface and the kaolinite $(00 \overline{1})$ surface doped by carbon atoms, the adsorption of a single water molecule weakened, with a weaker hydrogen bond formed.

(3) On the whole, whether using the kaolinite (001) surface or the kaolinite (001) surface, the charge transferred from the kaolinite to the water molecule. The electrons were mainly gathered around the $\mathrm{O}$ atoms of the water molecule and the kaolinite surface, respectively. After the kaolinite surfaces were doped with carbon atoms, the electron aggregation around the $\mathrm{O}$ atoms reduced. The occurrence of the electron accumulation made it possible for water molecules to adsorb on the kaolinite (001) surface and $(00 \overline{1})$ surface.

The results of this study are very important to deashing and improving the selectivity of mineral flotation and the concentrate grade, and provide some theoretical guidance to remove the coal kaolinite during the flotation process efficiently and explore the efficiency of dispersants and inhibitors used in industry. 


\section{Nomenclature}

All nomenclature and abbreviations are explained in alphabetical order, as follows:

$\begin{array}{ll}\text { BFGS } & \text { Broyden-Fletcher-Goldfarb-Shanno } \\ \text { CASTEP } & \text { Cambridge Sequential Total Energy Package; } \\ \text { DFT } & \text { Density Functional Theory; } \\ \text { DFT-D correction } & \text { Density Functional Theory Dispersion correction; } \\ \text { GGA-PBE } & \text { Generalized Gradient Approximation-Perdew-Burke-Ernzerhof; } \\ \text { XRD } & \text { X-ray diffraction; } \\ \text { XRF } & \text { X-ray Fluorescence Spectrometry. }\end{array}$

Author Contributions: Conceptualization, P.X.; methodology, P.X.; validation, P.X.; formal analysis, P.X.; investigation, P.X.; resources, P.X.; data curation, P.X.; writing-original draft preparation, P.X.; writing-review and editing, P.X.; visualization, P.X.; project administration, P.X.; funding acquisition, P.X.; supervision, R.M.; software, W.L. All authors have read and agreed to the published version of the manuscript.

Funding: This research was funded by the Fundamental Research Funds for the Central Universities (Grant No. 3142017102), the Scientific Research Project in Colleges and Universities in Hebei Province (Grant No. QN2020506) and the Nature Science Foundation of Hebei Province (E2019508097, E2020508029 and E2018508105).

Acknowledgments: We would like to thank Y. Han for providing the optimized kaolinite surface and the adsorption model of a single water molecule on the kaolinite surface. We also would like to thank T. Ma, J. Chen, and Q. Yang for providing the coal kaolinite samples.

Conflicts of Interest: The authors declare no conflicts of interest.

\section{References}

1. Xie, G. Mineral Processing, 3rd ed.; China University of Mining and Technology Press: Xuzhou, China, 2012; pp. 413-414, ISSN 978-7-81070-361-1.

2. Gui, X.; Cheng, G.; Liu, J. Process characteristics of heterogeneous fined mud in the coal flotation. J. China Coal Soc. 2012, 37, 301-307.

3. Gülsoy, Ö.Y. A simple Model for the Calculation of Entrainment in Flotation. Korean J. Chen. Eng. 2005, 22, 628-634. [CrossRef]

4. Szyszka, D.; Glapiak, E.; Drzymala, J. Entrainment-flotation activity of quartz in the presence of selected frothers. Physicochem. Probl. Miner. 2008, 42, 85-90.

5. Akdemir, Ü.; Güler, T. Role of some physical variables on gangue and water recovery in froth. In Proceedings of the 8th International Mineral Processing Symposium, Antalya, Turkey, 16 October 2000; pp. 257-261.

6. Akdemir, Ü.; Güler, T.; Yildiztekin, G. Flotation and and entrainment behavior of minerals in talc-calcite separation. Scand. J. Metal. 2005, 34, 241-244. [CrossRef]

7. Zhang, Z.; Liu, J.; Xu, Z.; Ma, L. Effects of clay and calcium ions on coal flotation. Int. J. Min. Sci. Technol. 2013, 23, 689-692.

8. Xi, P.; Ma, R.X.; Liu, W.L. Study on the Crystal Structure of Coal Kaolinite and Non-coal Kaolinite: Insights from Experiments and DFT Simulations. Symmetry 2020, 12, 1125. [CrossRef]

9. Xi, P.; Shi, C.; Yan, P. DFT study on influence of sulfur on the hydrophobicity of pyrite surfaces in the process of oxidation. Appl. Surf. Sci. 2019, 466, 964-969. [CrossRef]

10. Xi, P.; Ma, R.; Liu, W. Research on the Effect of Carbon Defects on the Hydrophilicity of Coal Pyrite Surface from the Insight of Quantum Chemistry. Molecules 2019, 12, 2285. [CrossRef]

11. Xi, P.; Liu, W.; Han, Y. Study on the mechanism of coal pyrite crystal lattice defects and floatability. J. China Coal Soc. 2016, 41, 997-1003.

12. Xi, P.; Wang, D.; Liu, W.; Shi, C. DFT Study into the Influence of Carbon Material on the Hydrophobicity of a Coal Pyrite Surface. Molecules 2019, 19, 3534. [CrossRef]

13. Xi, P.; Liu, W.; Yang, Z.; Chen, J. Quantum chemistry investigation on influence of carbon atom adsorption in carbon material to the coal pyrite hydrophobicity. J. China Coal Soc. 2017, 42, 1290-1296.

14. Zhao, J. The Research on Defect Formation Mechanism and Adsorption Property of Clay Minerals in Soft Rock. Ph.D. Thesis, China University of Mining and Technology (Beijing), Beijing, China, 2013.

15. Chen, J. Characteristics and Mechanism Research on Hydrophobic Aggregation of Fine Particles in High Muddied Coal Slurry Water. Ph.D. Thesis, Anhui University of Science and Technology, Huainan, China, 2017. 
16. Xi, P.; Zhao, X.; Liu, W.; Wang, D.; Hao, K.; Zhao, W. Experimental Study on Flocculation-Flotation of Coking Coal Middlings. Coal Eng. 2014, 47, 112-114.

17. Jiang, G.C.; Wei, Y.J.; Zhang, M.; Luos, S.J.; Yang, Z.; Pang, J.T. The Overview on the Gas-wetting Quantitative Evaluation Methods. Sci. Technol. Eng. 2012, 12, 5562-5567.

18. Segall, M.D.; Lindan, P.J.D.; Probert, M.J.; Pickard, C.J.; Hasnip, P.J.; Clark, S.J.; Payne, M.C. First-principles simulation: Ideas, illustrated and the CASTEP code. J. Phys. Condens. Matter 2002, 14, 2717-2744. [CrossRef]

19. Vanderbilt, D. Soft self-consistent pseudopotentials in a generalized eigenvalue formalism. Phys. Rev. B 1990, 4, 7892-7895. [CrossRef] [PubMed]

20. Tunega, D.; Gerzabek, M.; Lischa, H. Ab initio molecular dynamics study of a monomolecular water layer on octahedral and tetrahedral kaolinite surfaces. J. Phys. Chem. B 2004, 108, 5930-5936. [CrossRef]

21. Tkatchenko, A.; Scheffler, M. Accurate molecular wan der Waals interactions from ground-state electron density and free-atom reference data. Phys. Rev. Lett. 2009, 102, 073005. [CrossRef]

22. Han, Y.; Liu, W.; Zhou, J. Interactions between kaolinite Al-OH surface and sodium hexametaphosphate. Appl. Surf. Sci. 2016, 387, 759-765. [CrossRef]

23. Hu, X.; Michaelides, A. Water on the hydroxylated (001) surface of kaolinite: From monomer as adsorption to a flat 2D wetting layer. Surf. Sci. 2007, 602, 960-974. [CrossRef]

24. Mulliken, R.S. Electronic population analysis on LCAO-MO molecular wave functions. IV. bonding and antibonding in LCAO and Valence-bond theories. J. Chem. Phy. 1955, 23, 2343-2346. [CrossRef]

25. Šolc, R.; Gerzabek, M.H.; Lischka, H.; Tunega, D. Wettability of kaolinite (001) surfaces—Molecular dynamic study. Geoderma 2011, 169, 47-54. [CrossRef]

(C) 2020 by the authors. Licensee MDPI, Basel, Switzerland. This article is an open access article distributed under the terms and conditions of the Creative Commons Attribution (CC BY) license (http://creativecommons.org/licenses/by/4.0/). 